\title{
Hygroscopic growth of atmospheric aerosol particles based on active remote sensing and radiosounding measurements: selected cases in southeastern Spain
}

\section{J. Granados-Muñoz et al.}

Correspondence to: M. J. Granados Muñoz (mjgranados@ugr.es) 
a)

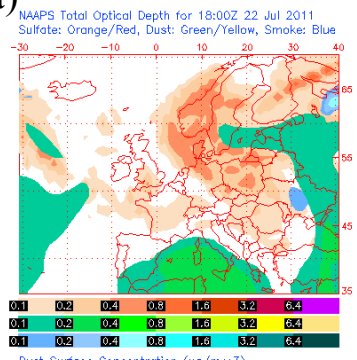

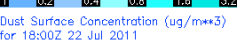

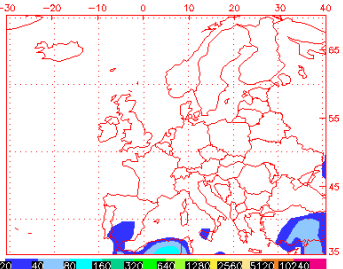

b)
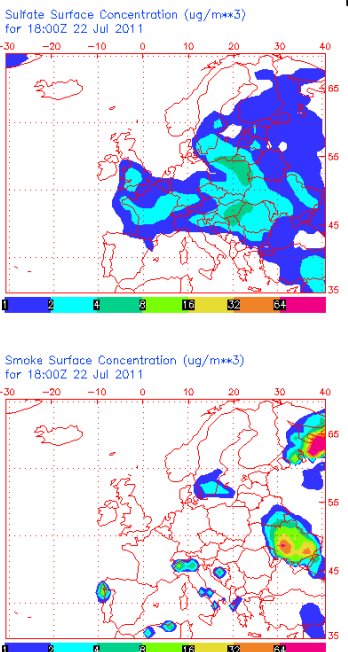

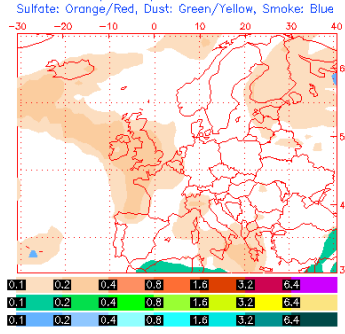

Dust Surface Concentration \{ $(4 \mathrm{~g} / \mathrm{m} * \mathbf{\mathrm { m } * 3 \}}$
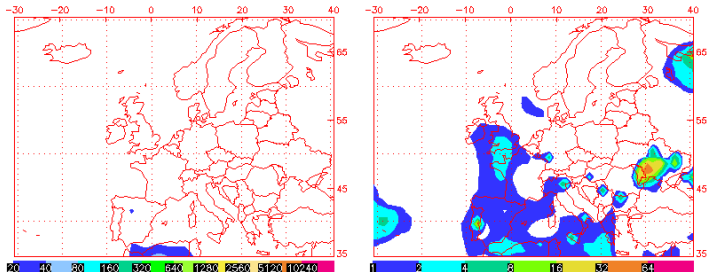

Figure S1. a)NAAPS model forecasts for $22^{\text {nd }}$ July 2011 at 18:00 UTC. b) NAAPS model output on $22^{\text {nd }}$ July 2013 at 18:00 UTC, which is the closest time to the radiosounding launch at 20:00UTC. 